\title{
Fatigue Life Resolution of the Steering Wheel Tie Rod of a LCV with FEA
}

\author{
Arif Senol SENER \\ Istanbul Gelisim University, 34315, Istanbul, Turkey, E-mail: arifsenolsener@gmail.com

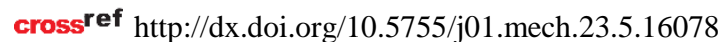

\section{Introduction}

The development time of vehicle is becoming shorter and shorter in last two decades. Concurrently, the demands set for the characteristics of a car (e.g. noise and vibration, fatigue life, crash behaviour etc.) are becoming increasingly stringent $[1,2]$. Fatigue testing are the most critical ones in all of these parameters according to the implementation time, because fatigue problem arises in the long-mileage as well [3-6]. Today widely fatigue methods applications of a vehicle are CAE (computer aided engineering), test-rig and test track is shown in Fig. 1 [4].

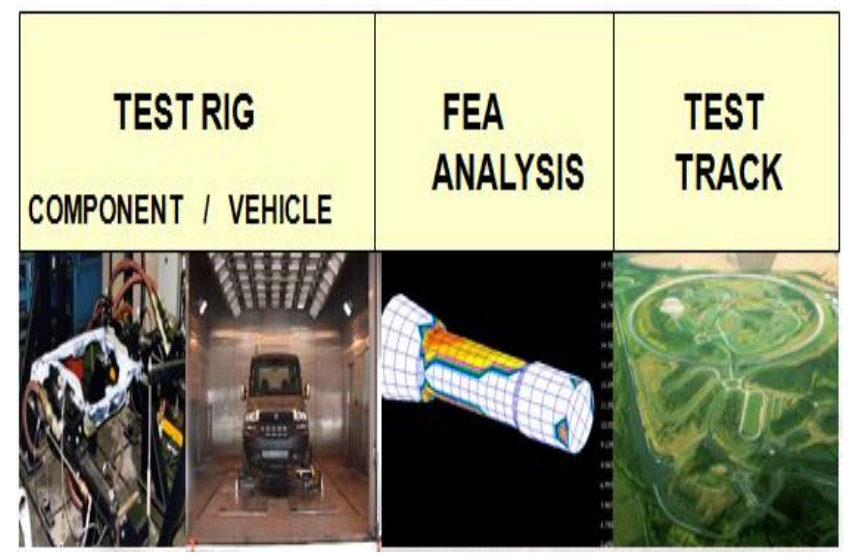

Fig. 1 Common fatigue methods

Each method has advantages and disadvantages. Especially accelerated road tests are closer to actual values, however it is more time consuming and over costing [7]. Additionally, reproducibility will always be poor due to the drivers, traffic conditions and the weather [8-10].

Although the test rig has advantageous for time and cost by comparison the accelerated road test, the test rig does not reflect the exact environmental impact (weather, and road conditions) and driver's errors $[4,5]$. FEA can be performed in shorter time when it is compared to the other methods and it provide proper design solutions [11, 12].

In brief, more efficient methods must be used (Van Oosten Slingeland 1999) [1]. So as to decrease the test time and project cost, one or more methods are implemented by automobile manufactures. Analytical prediction and CAE (i.e. virtual testing) with the traditional testing methods must be combined to shorten the design time, to minimize the cost and to improve the quality (i.e. physical testing) [1]. Life time of a vehicle which is affected by the load spectrum i.e.; type of usage, environmental and operational conditions, should be determined by automobile Co. [3]. Actually, the most important and difficult stage is how to determine the characteristic load spectrum because whole methods used in the earlier were either too weak or too heavy [6].

The most popular method used to determine load spectrum for the entire life of a vehicle is the customer usage based method [4-6].

In a customer usage study includes dry and wet ground usage of tractor and agriculture as well as non-agriculture tractor usage and also regional tractor usage examination is a study on a tractor usage in India, which was performed by ETEC (Eicher Tractors Engineering Centre) and ARIA (Automotive Research Association of India) [13]. In a research, FIAT Co. achieved a customer usage study for Italy and Brazil. Brazil has not special proving ground. FIAT Co. compared Italy' profile effects of proving ground and Brazil' public roads for customer usage effects on the vehicles by using frequency based fatigue life [14]. In another research performed by FIAT Co., they explored the costumer usage of Ritmo 60 and Tipo1372 models [15]. TOFAS Co. defined Turkish LCV customer usage profile in 2001. The Turkey's roads fatigue characteristic effect on the vehicle was determined and simulation of MP values has been performed by designing accelerated test tracks for reliability and fatigue testing around the producers [4,5].

In the previous studies about in 2006, a SUV's steering wheel tie rod breaking problems were investigated [16]. In 2013 Static stress and natural frequency calculations of a steering wheel tie rod and steering wheel arm at an angle was performed by Patil. M.A $[17,18]$. A rod link-age parts of a minivan in 2014 was made separately by the modelling. The computer analysis was performed and analytical improvements have been made according to $2000 \mathrm{~N}$ axial loads concerning in the specification of the firm and the warranty is based on the application documents $[19,20]$.

Components such as steering tie rod are subjected to fatigue failures due to cyclic load arising from various driving conditions $[21,22]$. Tie rod ends in the vehicle steering mechanisms, it provides forwarding function to the wheel from the steering links. Engineering, design and manufacturing processes that require the roughness in each of this equipment, any faults may be lead to stability and aquatic problems during driving. Sudden fracturing and breaking as less encountered cases the risk of accidents is greater. Faults are observed as a result of improper material selection, design deficiency, fatigue and deformation of component.

In this study, the road fatigue characteristics were totally measured from one city to another city to find out the effect of different roads and to form new fatigue roads that are necessary during the process and pre-series production around the factory. In the following sections, to determine a test track for a light commercial vehicle that benefited a lot from sensor dates that one of steering wheel tie rod sensor, on test methodology is described. 


\section{Experimental technique}

A corresponding load spectrum, which include all load values that is encountered in the normal use of a component or a vehicle, should be used for accelerated fatigue testing. The life span of a component generally influenced by loading conditions during the usage [3]. A representative load spectrum must be composed for design and process verification and reliability test $[3,23]$. Recently, two methods as questionnaire and black box are used to determine customer usage of a vehicle $[6,9,10]$.

\subsection{Black box method}

In this method according to different customer profile (age, education level, job etc.), owners of vehicles are determined by the manufacturer factory. Black boxes are a kind of data logger that collect signals of physical parameters and record into its memory which are fixed on vehicles of voluntary owners by the manufacturer. The data is measured every week then statistical results are obtained and evaluated by the manufacturer factory. Measurement time of this method takes about 3 years, so this method is expensive and time-consuming. Also driving errors is more because customers know that they are monitored by factory [9, $15]$.

\subsection{General description of a questionnaire method}

In a survey study performed by independent firm, it establishes a customer usage profile which contain used road types, the amount of the vehicle's load, customer training profile, aim of vehicle usage etc. [4, 6]. The road characteristics are determined by doing a road test with equipped vehicle or vehicles and driver or drivers also at different vehicle loads on specified road map [3, 6]. Each collected row data are processed with the signal processing methods after that processed signal are subject to signal statistical counting method [3, 23]. Normalizing (generally $1000 \mathrm{~km}$ ) each signals fatigue effects is rendered so that could be compared meaningfully. Thus, it is decided that which signal will be used which will be canceled then for each signal, general mission profile is determined by arithmetic manipulation and road segment percentage. The method depends on processes that the resulting fatigue damage from mission profile that correspond to same fatigue effect of the accelerated test (test rig, accelerated test track, FEA etc.) In this way the test tracks are standardized [6]:

$$
A_{1}\left[M_{1}\right]+A_{2}\left[M_{2}\right]+\ldots+A_{n}\left[M_{n}\right]=[C]
$$

where $\left(A_{1}, A_{2}, A_{3}, \ldots, A_{\mathrm{n}}\right)$ are the multipliers of test data, $\left(\left[M_{1}\right],\left[M_{2}\right], \ldots,\left[M_{\mathrm{n}}\right]\right)$ are the matrix of test measurements and $[C]$ is the matrix of customer target measurements [6].

\section{Analytical methods}

The row data acquisitions on the defined road map was done with a FIAT Doblo Passenger vehicle. In Fig. 2 the algorithm of the study is presented.

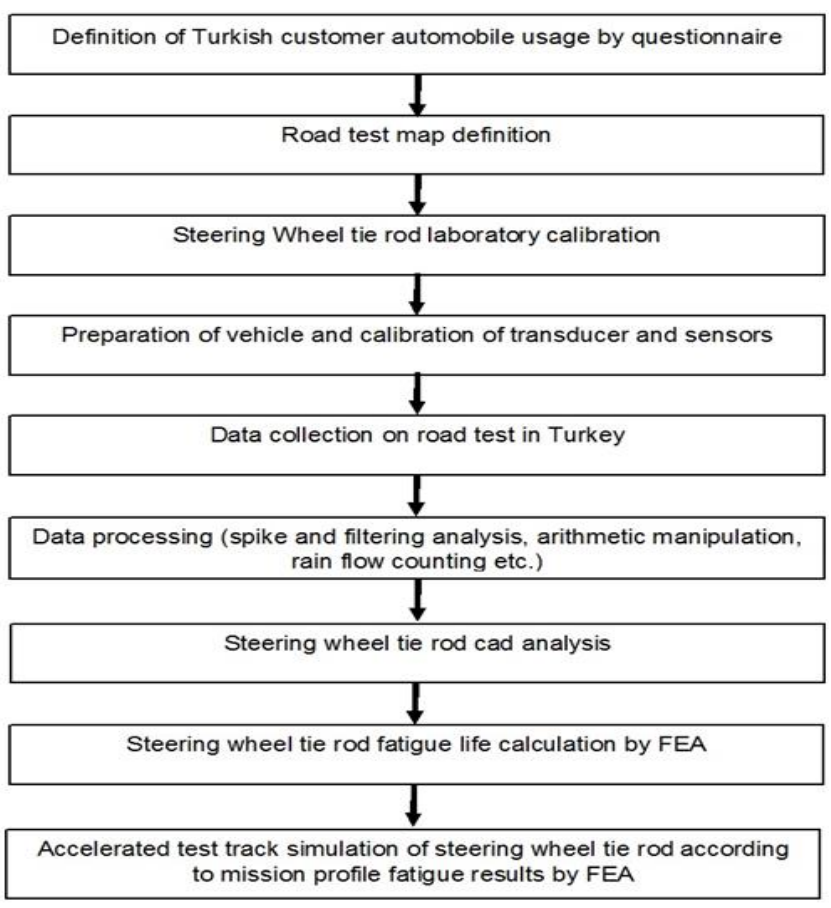

Fig. 2 Algorithm of the study

3.1. Turkish profile questionnaire application

Questionnaire method is chosen due to low cost, short time consuming and a faster data collection and statistically all transactions can be done on collected data according to black box method. Questionnaire of Turkish customer usage profile of LCV was performed face to face by defined deals of the manufacturer in Turkey and customers of brand [5]. Then the collected data were statistically elaborated.

\subsection{Data acquisition to form the mission profile target}

The calibration of the all sensors were performed in the fatigue laboratory before assembling them on the test vehicle. Test had been done with equipped vehicle in the factory's test track for checking to see how the sensors worked before beginning MP test in Turkey.

Strain of the components caused by different maneuvers and road roughness were measured by strain-gauges that respectively equipped on the components of the test vehicle; steering wheel tie rod, driving shaft and leaf spring.

Vertical acceleration caused by different maneuvers and road roughness were measured by accelerometers that were fixed at the bottom of shock absorber. Lateral and longitudinal body accelerations of the test vehicle were measured using two accelerometers positioned at the center of mass of the vehicle.

Breaking maneuvers was measured by recording pressure in the hydraulic circuit.

Two displacement sensors were used to define body movements.

Ultimately the test vehicle speed, engine crank shaft rpm and temperatures (12 thermocouples) were digitally recorded [5].

The row dates of MP were collected on the designed road test map driving over customers in the condition of vehicle at full load including one expert driver, one test engineer, test equipment's and loads. In Fig. 3 demonstrate 
that the steering wheel tie rod with strain-gauge applied before and after fixing on the test vehicle.

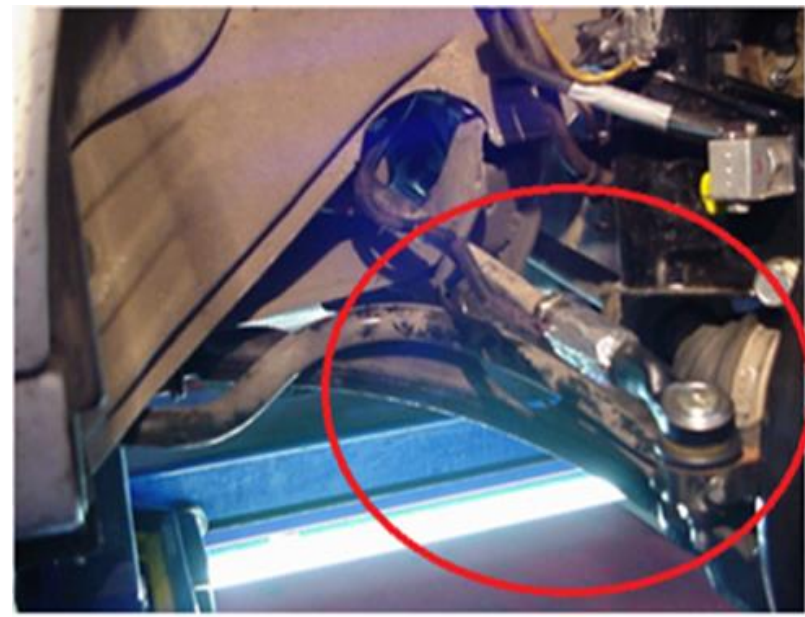

Fig. 3 Steering wheel tie rod with strain-gauge assembled on the vehicle

\subsection{Data processing}

The fatigue data collected in time domain is not measured directly from the external load in place of this it is measured on parts reaction of vehicle by sensors [24]. Acquiesced row data were elaborated by n Soft computer programs in respectively; spike analysis, frequency analysis, filtering, arithmetic manipulation and statistical counting operation [25].

Spike Analysis: Throughout data acquisition on roads with the test vehicle several "spikes", were formed inside the collected data by unexpected external reasons like traffic radar etc. All collected signals were detected by visually using $\mathrm{n}$ Soft spike detection and spikes were discarded by visually and the statistical $n$ Soft method [25].

Filtering: Generally, the vehicle chassis components vibration due to road effects or maneuvers come out between $40 \mathrm{~Hz}$ and $60 \mathrm{~Hz}$ in frequency domain. It is more common used frequency is below $100 \mathrm{~Hz}$ for fatigue test track simulation [10]. In figure 4 above the $100 \mathrm{~Hz}$ frequency of dates were subtracted by using low -pass filter toolbar of $\mathrm{n}$ Soft filtering program $[4,5,10,25]$.
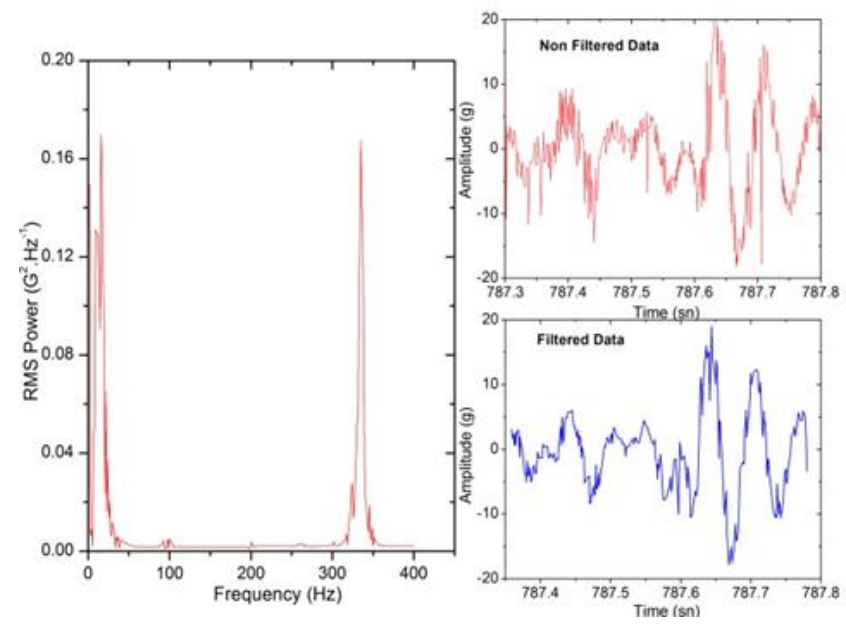

Fig. 4 Data filtering above $100 \mathrm{~Hz}$ stationary at beginning and at end of the tests, the collected data are insignificant in term of fatigue analysis. Consequently, these data were removed form original signals by using arithmetic manipulation tool bar of nSoft program [25].

Statistical counting of signal: Road signals are identified by random and stationary signals that are timevarying. In order to make two signal comparison it is necessary made the signals independent from time. Rain flow cycle counting method which takes into account mean amplitude was used for the steering wheel tie rod strain-gauge signal data $[26,27]$.

Forming mission profile target: Each acquired signal was normalized to $1000 \mathrm{~km}$ due to the roads had various distance in order to be made for comparison [4, 5, 23]. Normalized road signals were classified in respectively; city, intercity, mountain and highway. Then each road signal within its class were averaged arithmetically. Averaged $1000 \mathrm{~km}$ signals of each road class were extrapolated $200.000 \mathrm{~km}$. By multiplying Turkish automotive customer usage percentage with $200.000 \mathrm{~km}$ each road class's signals values, a single steering wheel tie rod signals of MP were formed. Fig. 5 shows that the MP histogram of steering wheel tie rod axial data for $200.000 \mathrm{~km}$. In the histogram given in Fig. 5 the maximum load range reaches to 870 daN, while it's the mean of this load is low level. This maximum load cycle is very low. In the low range level cycles mean stress are very dominant. This is caused by road surface irregularity and small steering maneuver.

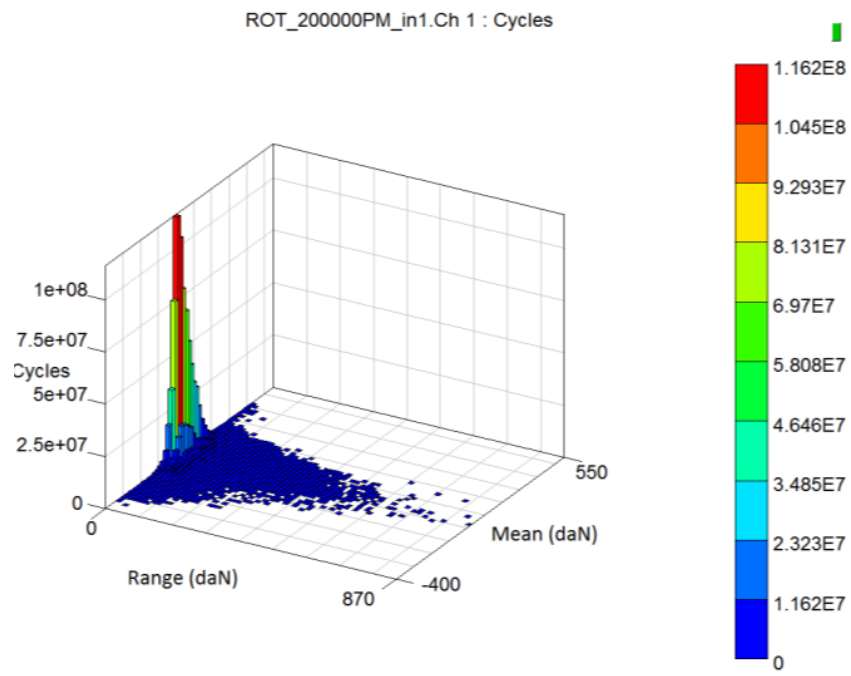

Fig. 5 Steering wheel tie rod Mission Profile rain-flow histogram $(200.000 \mathrm{~km})$

Simulation of Mission Profile: The accelerated test track for the fatigue simulation was constructed using heavily damaged surfaces and manoeuvres to decrease the test time. Though force, displacement, and acceleration are very important parameters for fatigue testing, the gear change rate, brake pressure, brake application quantity and engine torque parameters should also be taken into account for a accelerated test track simulation. For this reason, one short accelerated test track that included all kinds of surfaces and characteristics was defined. This road was extrapolated to $30.000 \mathrm{~km}$ for fatigue simulation that corresponded to $200.000 \mathrm{~km}$ under normal usage $[4,5]$.

Arithmetic manipulations: When the vehicle is 


\section{FEA Analysis}

\subsection{Steering wheel tie rod CAD model}

The CAD model of the steering wheel tie rod was designed in SolidWork software program is presented in Fig. 6.

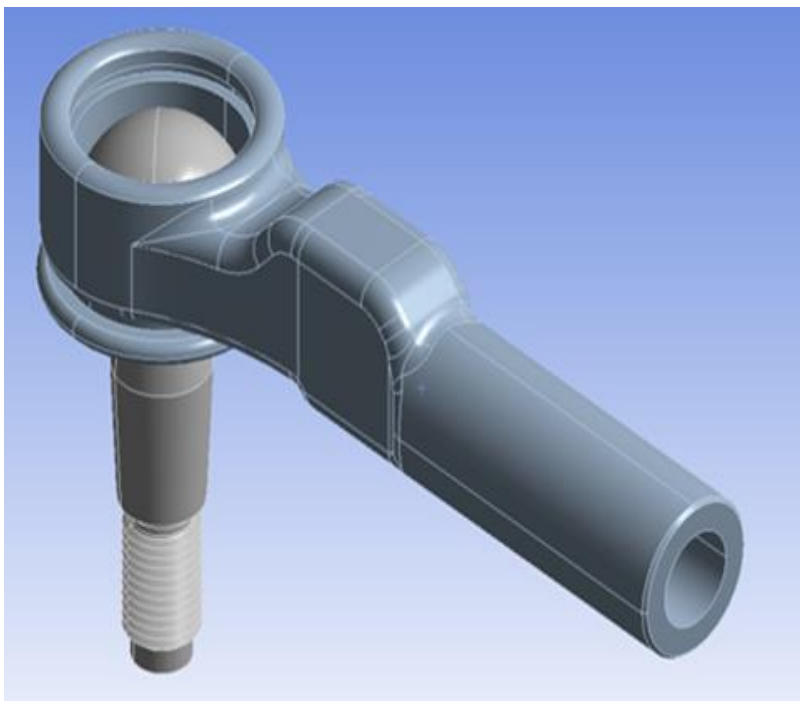

Fig. 6 CAD model of steering wheel tie rod

As the steering wheel tie rod has a complex structure especially on neck of the rod surface, the solid elements were used for precise modelling [28].

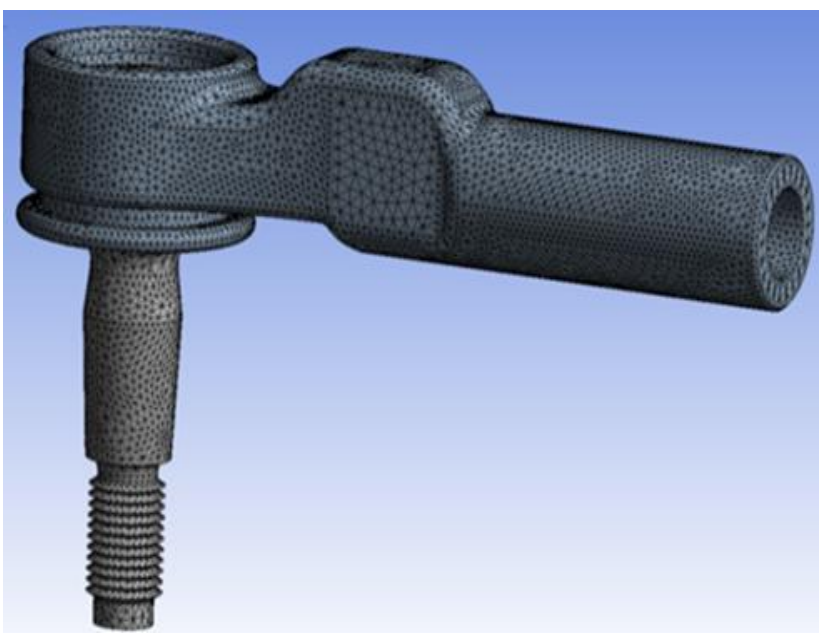

Fig. 7 Finite element model of the steering wheel tie rod

Total tetra elements and nods quantity were improved in order to make more precise calculation especially around neck of the rod that tis very complex geometry. Then 3D CAD model of the steering wheel tie rod was exported to ANSYS program to perform FEA analysis. 3D CAD model of steering wheel tie rod was formed from 72233 tetra hexagon elements and 124827 nodes is presented in Fig. 7 [29].

\subsection{Boundary condition}

In Fig. 8, the boundary conditions of steering wheel tie rod are demonstrated. The red arrow at the right surface of steering wheel tie rod represents the applied axial pulling load direction which is allowed free only ex-tension axis pulling side [29].

The ball joint connection between the surface and the spherical guide surface around 3 degrees of freedom (DOF) has been defined links. Because the steering wheel tie rod is fixed from each side both steering wheel cramayer shaft and the rack at the knuckle freedom is allowed to return are depicted. Here, in three axes of translational freedom $(x, y, z)$ of linear movement, the freedom of rotation in three axes $(R x, R z, R z)$ represents rotation.

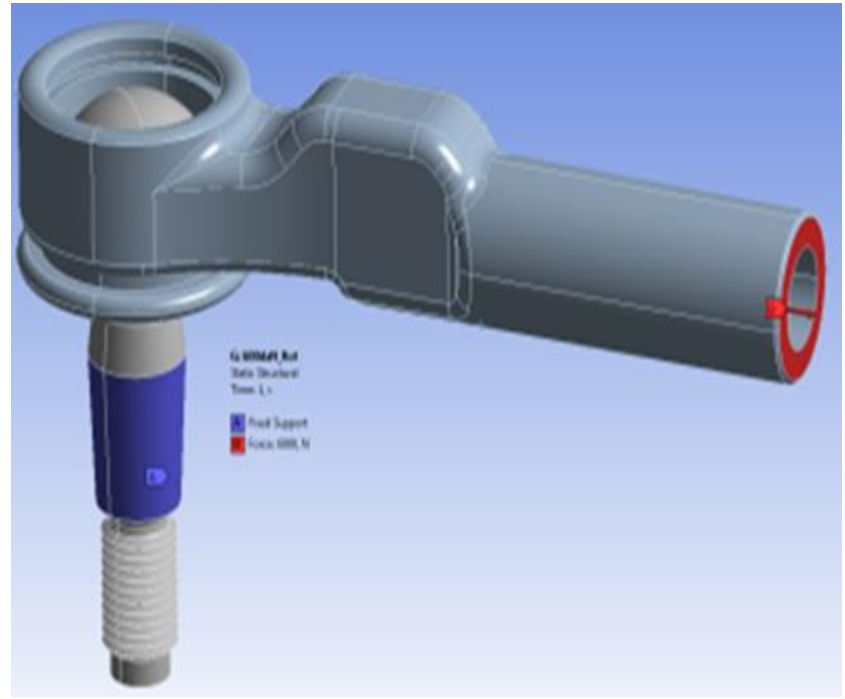

Fig. 8 Boundary conditions

\subsection{Static and fatigue analysis}

The linear static analysis of the steering wheel tie rod is performed by using most critical load acquired throughout the road tests in Turkey and it is shown in Fig. 9.

The dynamic data of the route given in Fig. 9 was collected in the south of Turkey in between Muğla and Kaş extra urban route which has characteristic of very sharp and very frequent curving. The maximum value in this data was used to static analysis of the steering wheel tie rod. The reason of using this data which is the maximum values in collected data in Turkey.

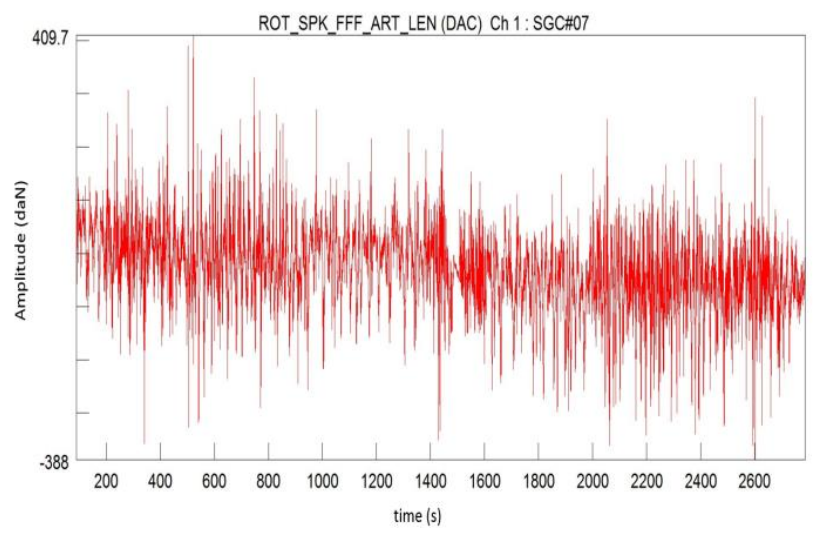

Fig. 9 Critical road data axial force -time signal of steering wheel tie rod

For the statistical analysis of steering wheel tie rod, the maximum load data, measured during the road test, horizontally 900 daN ranges axial pulling forces was applied from the side of steering wheel tie rod connection by using 
the FE model.

In Fig. 10, it can be seen that after applying $900 \mathrm{daN}$ axial pulling force on the spherical joint branches $0.0061938 \mu \varepsilon$ strain was derived. The nominal stress is determined as $1397 \mathrm{MPa}$ at node 5796 according to the VonMisses method using the most critical load condition in the linear static analysis [30, 31].

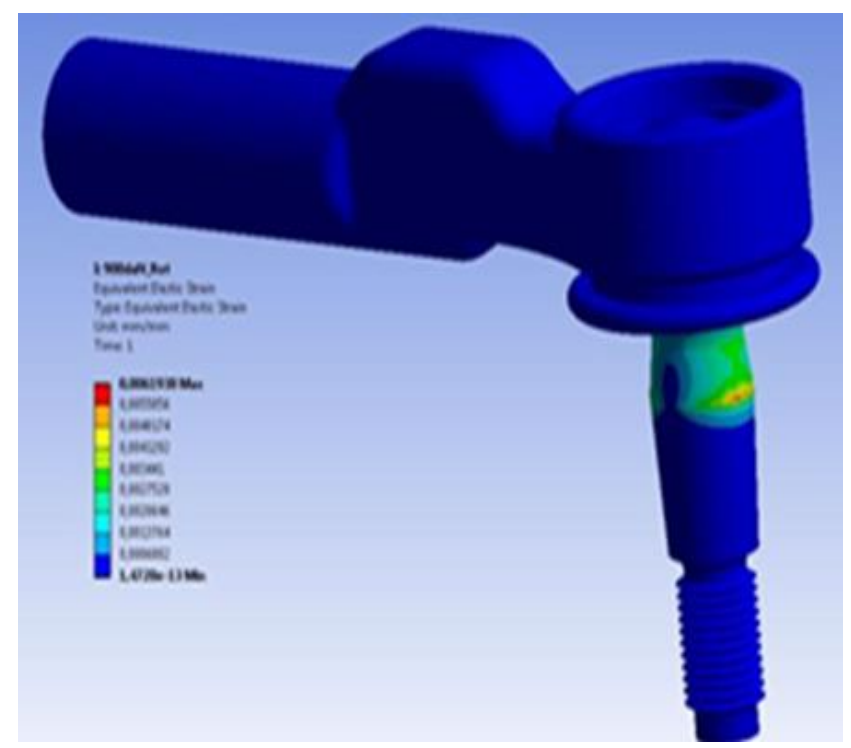

Fig. 10 Static strain analysis of steering wheel tie rod according to 900 daN axial force

The comparison of strain values obtained from real bench test in laboratory and CAD static analysis of steering wheel tie rod is represented in Fig. 11. The vertical axis show axial force loads applied physically where-as the horizontal axis show obtained unit from normal strain on the steering wheel tie rod. Blue square symbols represent axial real force applied physically on the steering wheel tie rod and red triangle symbols show the results of CAD static analysis. It is obtained from the physical test and computer analysis under $100 \mathrm{daN}$ as $0.0009427 \mu \varepsilon$ and $0.0006882 \mu \varepsilon$, respectively.

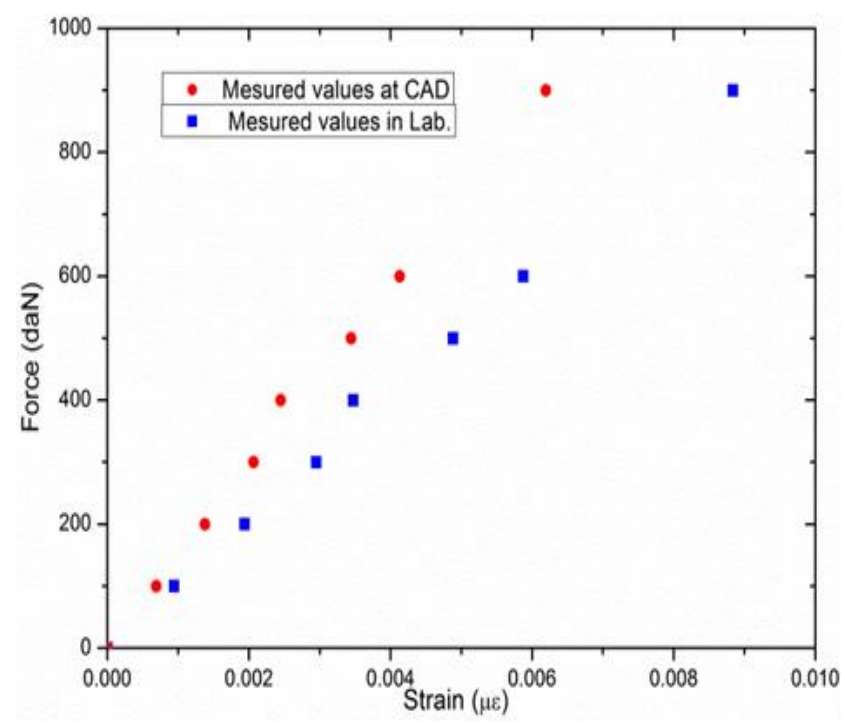

Fig. 11 Steering wheel tie rod real bench test and CAD static analysis strain values comparison

The rain-flow histograms of steering wheel tie rod force load distribution of the accelerated test track $30.000 \mathrm{~km}$ are illustrated in Fig. 12.

The data of accelerated fatigue $30000 \mathrm{~km}$ route in the histogram given in Fig. 12 was formed using the data which were collected around the factory where the LCV is produced.

This data is consisting of city, extra urban, highway, mountain and a little amount of bad roads i.e.; pothole, bump, heavy payment etc.

The 3D histogram of the accelerated fatigue test route peak value was below under the MP maximum value is given in Fig. 5 .

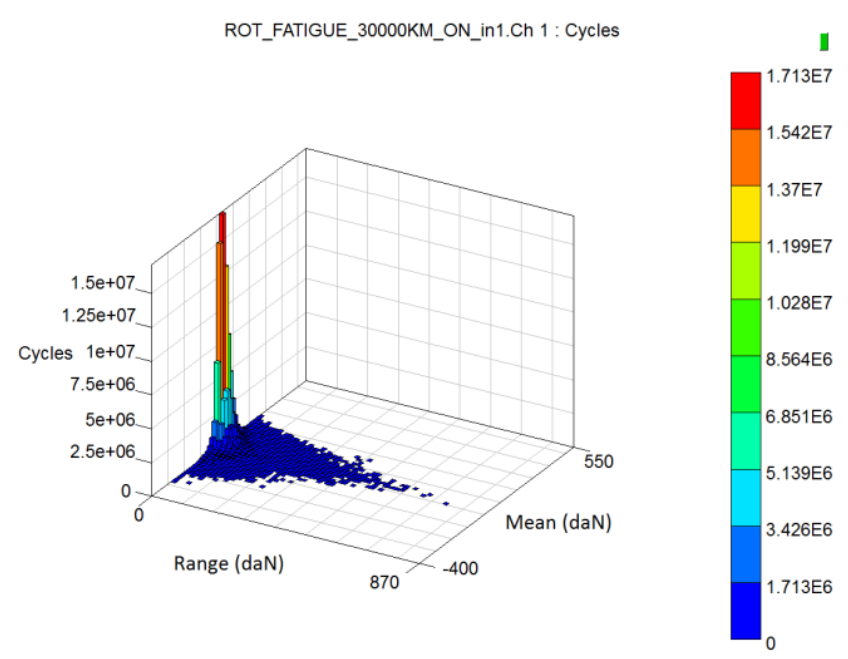

Fig. 12 Accelerated test track rain-flow histogram $(30000 \mathrm{~km})$

Fig. 13 shows the Wohler line $S$ (stress) - $N$ (number of cycles) of the material characteristics of the steering wheel tie rod [22].

The Wohler line of steering wheel tie rod given in Fig. 13 was formed by using Ansys program's library referencing picture of the production component and hot forging processing.

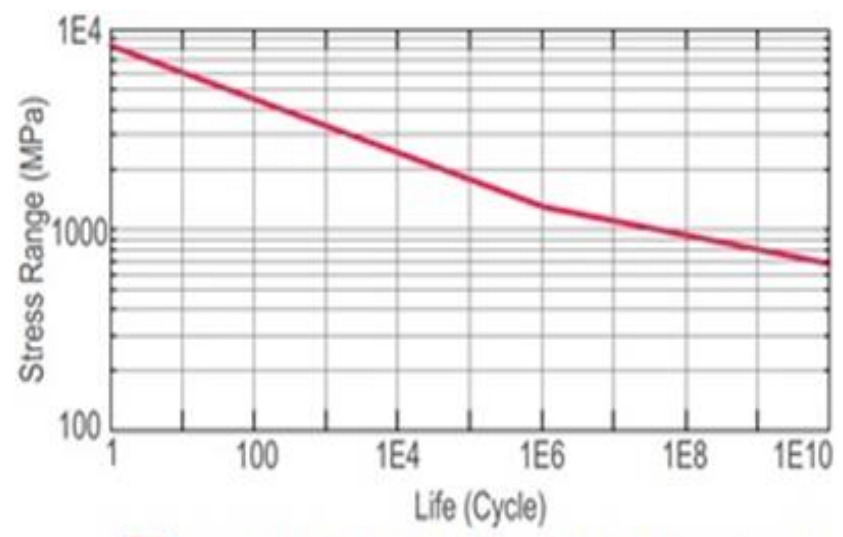

C35 SRI1:8571 93 MPa b1:-0.1338580978 b2:-0.07172986021 NC1:1[6

Fig. $13 S$ - $N$ curve of the steering wheel tie rod

The stress life method is chosen for the data obtained from different kind of the roads in Turkey. Because the maximum stress is much lower than the actual yield stress of the steering wheel tie rod material yield stress. It is identified that measured stress values are much lower than 
the material yield stress $[30,32]$

\subsection{Plamgren-Miner analysis}

Plamgren-Miner Analysis Method is based on cumulative damage models for fatigue failures. This meth-od approve the fatigue damage as linear. In this theory, a component is exposed to cn cycles at stress $\sigma_{\mathrm{n}}$.

$$
c_{1}, c_{2}, \ldots, c_{n}: \text { cycles }
$$

$\sigma_{1}, \sigma_{2}, \ldots, \sigma_{n}:$ stresses

It is possible to obtain the number of cycles to failure, $C_{1}$ at $\sigma_{1}, C_{2}$ at $\sigma_{2}, \ldots, C_{n}$ at $\sigma_{n}$ from Wöhler Line for any material. The fractional damage at stress level $\sigma_{i}$ is simplified $c_{i} / C_{i}$, so that the Palmgren-Miner rule show fatigue failure occurs when:

$$
\sum_{i=1}^{n} \frac{c_{i}}{c_{i}}=1
$$

Fatigue CAD analysis of steering wheel tie rod for fatigue damage is illustrated in Fig.14 and there is no fatigue damage is occurred [33].

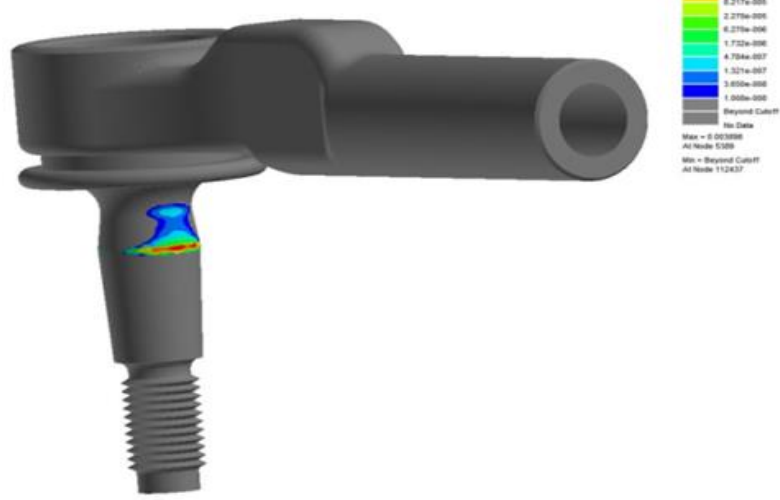

Fig. 14 Fatigue damage of steering wheel tie rod applying $200000 \mathrm{~km} \mathrm{MP} \mathrm{data}$

\section{Results and discussion}

The automotive usage of Turkish customer for a LCV is described from the questionnaire results. The mission profile has $50 \%$ city, $24 \%$ intercity, $20 \%$ highway, and $6 \%$ mountain have been derived from questionnaire for the passenger's version of these vehicles. In the comparison result of the derived data from Turkey with one of the another European country, the most important difference is found as the amount of city LCV usage as 50\% in Turkey. Aims of LCV usage are work-to-work and home to work in Turkey $[5,10]$.

In Fig. 15, the steering wheel tie rod load spectrum of the Turkish MP $(200.000 \mathrm{~km})$ matched with blue color, the reliability roads $30000 \mathrm{~km}$ matched with red color and the accelerated fatigue test track $30000 \mathrm{~km}$ matched with light green color are shown.

The vertical axis in Fig. 15 display steering wheel tie rod force affected during the makeovers of the curving while the horizontal axis shows logarithmic values of cycles.

These load spectra have been verified in terms of a fatigue damage analysis according to the Palmgren-Miner damage rule. According to the MP test in Turkey, 900 daN as the maximum axial force load is reached, while the accelerated test tracks were identified as $800 \mathrm{daN}$ max. Accelerated test track and MP curve are very close to each other at every force level except $100 \mathrm{daN}$. This difference is caused by road irregularity and light curving manoeuvres. This difference does not have a great fatigue effect in terms of fatigue life of the component. The damage ratio between the accelerated test track $(30.000 \mathrm{~km})$ and the MP (200.000) km is found as 0.78 .

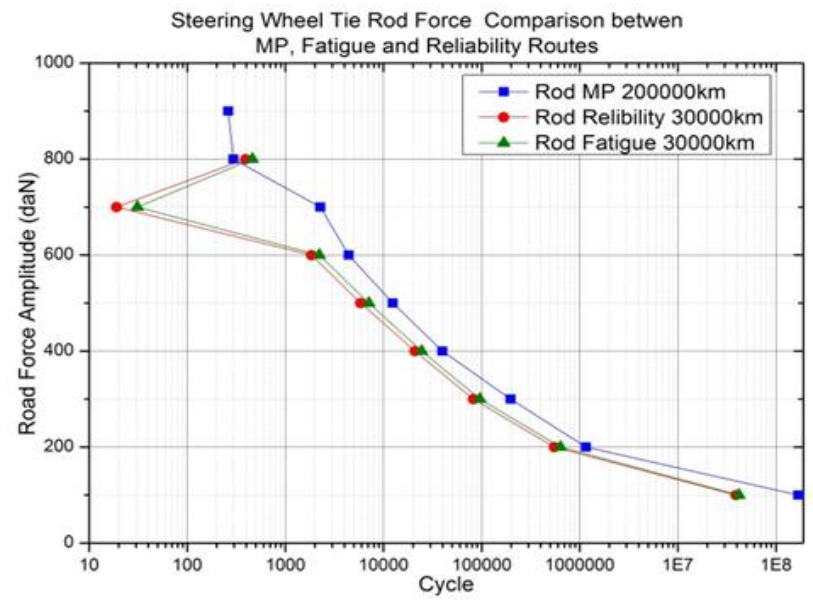

Fig. 15 Comparison of steering wheel rod data between mission profile and accelerated tracks

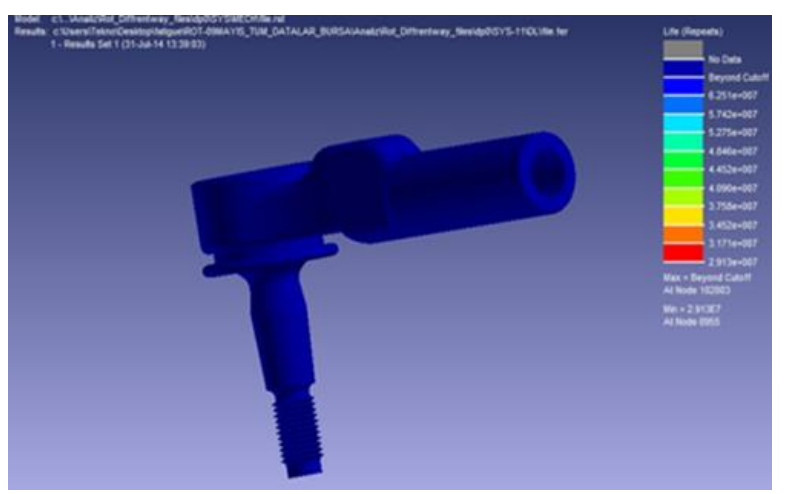

Fig. 16 Fatigue life calculation according to one high-way steering wheel tie rod data $200000 \mathrm{~km}$

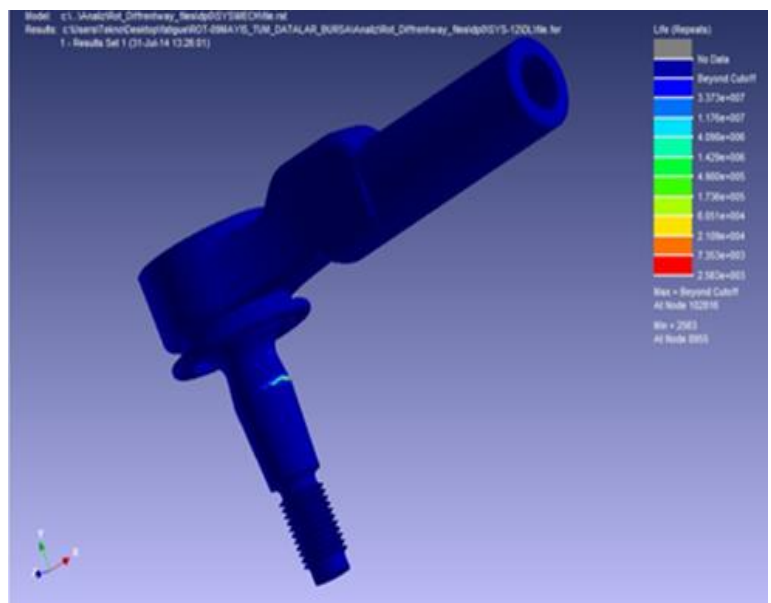

Fig. 17 Fatigue life calculation according to one ex-urban usage steering wheel tie rod data $200000 \mathrm{~km}$ 
Figs. 16 and 17 shows in respectively the CAD fatigue life analysis of critical city and highway etc. usage data $200,000 \mathrm{~km}$ of steering wheel tie rod.

When fatigue life of highway $200.000 \mathrm{~km}$ is referenced at node 8955 , the rate of other routes is found:

- City/highway= 807, 5/2,913e7=2,772e-5;

- Ex-urban/ highway = 2653/2,913e7=,9,1074e-5;

- Mountain/highway=853/2,913e7=3,8896e-5.

\section{Conclusions}

1. Turkish LCV usage profiles has been obtained both passenger and cargo version of the vehicle.

2. The results of the survey showed that local LCV users automotive city usage in Turkey nearly doubled comparing one of the European countries' values [5, 10].

3 . The aim of usage of the vehicle by Turkish customers was determined that the vehicles were more used for home to work and work to work.

4. This light commercial vehicle of the Turkish customer profile (MP_200.000) was created for each measured physical characteristics.

5. According to MP values, the accelerated test treks i.e; the reliability route and second fatigue route has been constructed around the factory and these routes has been standardized by the weighted average method for nonstressed components and miner rule is referenced for the stressed components. The Fig. 15 shown that it generally understood to be a good convergence between the mission profile and the accelerated test tracks values.

6 . It has been proved that the neck of steering wheel tie rod being a complex structure, more accurate results has been obtained for meshing of the component by using triangle 3D element.

7. It was found that the $\mathrm{S}-\mathrm{N}$ fatigue method is more convenient in terms of fatigue analyses for the steering wheel tie rod. Because each amplitude of physical stress is quite below Wöhler curve of part and total cycles quantities are too much.

8. It has been determined that fatigue damage has not been occurred on steering wheel tie rod by applying MP values and accelerated test tracks value.

9. It has been perceived that computer aided analysis can be used as an alternate for the research be-cause the outcomes that were achieved were pretty especially in terms of cost and development process time.

\section{Acknowledgement}

TOFAS supported the research.

\section{References}

1. Huizinga, F. T. M. J. M.; Van Ostaijen, R. A. A.; Van Oosten Slingeland, A. 2002. A practical approach to virtual testing in automotive engineering, Journal of Engineering Design 13(1): 33-47. http://dx.doi.org/10.1080/09544820110090304.

2. Fourlaris, G.; Ellwood R.; Jones T.B. 2007. The reliability of test results from simple test samples in predicting the fatigue performance of automotive components, Materials \& Design 28(4): 1198-1210. http://doi.org/10.1016/j.matdes.2006.01.005.
3. Grubisic, V. 1994. Determination of load spectra for design and testing, International Journal of Vehicle Design 15(1-2): 8-26.

http://dx.doi.org/10.1504/IJVD.1994.061902.

4. Şener, A.Ş. 2014. Finite element based vehicle com-ponent fatigue life assessment according to a customer usage profile, Materials Testing 56(3): 198-207. http://dx.doi.org/10.3139/120.110543.

5. Şener, A.Ş. 2003. Fatigue life determination of the leaf spring on the light commercial vehicle according to Turkish Mission Profile, Yildiz Technical University. 131p. (in Turkish).

6. Mainieri, G.; Ensor, D.F. 1999. Case Study - Complete Customer Usage Profiling Example Raw Data through Track Correlation to Accelerated Rig Drive in '4' Days., Iveco (Italy) - nCode (UK). Avaliable from inernet:http://web.mscsoftware.com/support/library/conf/auto00/p05500.pdf.

7. Grubisic, V. 1985. Criteria and methodology for lightweight design of vehicle components, Fraunhofer-Inst. für Betriebsfestigkeit. $20 \mathrm{p}$. http://dx.doi.org/10.4271/850367.

8. Oelmann, B. 2002. Determination of load spectra for durability approval of car drive lines, Fatigue \& Fracture of Engineering Materials \& Structures 25(12): 11211125.

http://dx.doi.org/10.1046/j.1460-2695.2002.00604.x.

9. Marchesani, M.V.C.; Parmigiani, F. 1979. Integrated method to define the mission profile of a passenger car FIAT Auto SpA. (in Italian).

10. Pizzari.V. 1998. Ricerca del profilo di Missionevetture segment B Turchia, Turkish Ciklo Relazione Prot. No. 1 -1998, D.T.S.V. Affidabilita' e TerreniProva LaboratorioMisure. (in Italian).

11. Corporation, M. MSC. 1998. Software GmbH/Fatigue V8 User Manuel. Avaliable from internet: https://simcompanion.mscsoftware.com/infocenter/index? page $=$ content\&id=DOC 9240 .

12. Ahlin, K., Granlund J., Lindstrom F. 2004. Comparing road profiles with vehicle perceived roughness, International Journal of Vehicle Design 36(2-3): 270-286. http://dx.doi.org/10.1504/IJVD.2004.005360.

13. Paul, P. K., Dunga, R. K., Verma, A., Mannikar, A.V., Raju, S. 2001. Techniques for Accelerated Design Validation of Tractor Chassis, SAE Technical Paper. http://dx.doi.org/10.4271/2001-26-0050.

14. D'Aprile, F., Macri, M., Bruder, T., Liefooghe, C. 2001. Structural characterisation of a vehicle on a rig test versus different road profiles: analysis of experimental results, J. Motor Car Eng. ATA. 54(7-8): 251-258.

15. Fantacchiotti, M., Vianello, M. 1994. Gradual improvement to the vehicle reliability up to the target value, 4th International Conference on new Design Frontiers for More Efficient, Reliable and Ecological Vehicles, Florence, Italy, Mar 16-18.

16. Falah, A., Alfares, M., Elkholy, A. 2007. Failure investigation of a tie rod end of an automobile steering system, Engineering Failure Analysis 14(5): 895-902. http://dx.doi.org/10.1016/j.engfailanal.2006.11.045.

17. Patil, M. A., Chavan D., Ghorpade, M.K.U.S. 2013. FEA of Tie Rod of Steering System of Car, International Journal of Application or Innovation Engineering and Management 2(5): 222-227 (In Turkish) Available from internet: 
http://ijaiem.org/Volume2Issue5/IJAIEM-2013-05-24052.pdf.

18. Kim, J.K.; Kim, Y.J.; Yang, W.H.; Park Y.C.; Lee K.H. 2011. Structural design of an outer tie rod for a passenger car, International Journal of Automotive Technology 12(3): 375-381. http://dx.doi.org/10.1007/s12239-011-0044-6.

19. Pehlivan, M.K.; Ozsoy, M. 2014. Computer aided structural analysis of rot head, Bilecik Şeyh Edebali Universitesi Fen Bilimleri Dergisi 1(1): 45-51 (in Turkish)

20. Regulation on warranty application basis (in Turkish). 2014. Available from internet: http://goo.gl/v4awJY.

21. D'Ippolito, R.; Hack, M.; Donders, S.; Hermans, L.; Tzannetakis, N.; Vandepitte, D. 2009. Improving the fatigue life of a vehicle knuckle with a reliability-based design optimization approach, Journal of Statistical Planning and Inference 139(5): 1619-1632. http://dx.doi.org/10.1016/j.jspi.2008.05.032.

22. Azrulhisham, E.A.; Asri, Y.M.; Dzuraidah, A.W.; Abdullah, N.N.; Shahrum, A.; Hassan, C.H. 2010. Evaluation of fatigue life reliability of steering knuckle using pearson parametric distribution model, International Journal of Quality, Statistics, and Reliability. http://dx.doi.org/10.1155/2010/816407.

23. Dreßler, K.; Speckert, M.; Müller, R.; Weber, C. 2009. Customer loads correlation in truck engineering: Fraunhofer-Institut für Techno-und Wirtschaftsmathematik, Fraunhofer (ITWM). Available from internet https://kluedo.ub.uni-kl.de/frontdoor/index/index/year/2009/ docId/2072.

24. Gobbi, M.; Mastinu, G. 1998. Expected fatigue damage of road vehicles due to road excitation, Vehicle System Dynamics 29(1): 778-788. http://dx.doi.org/10.1080/00423119808969608.

25. MSC. Software GmbH nCode volumes 5.2 User Manuel. 1999. Available from internet: www.ncode.com

26. Standard practices for cycle counting in fatigue analy-sis ASTM Standard E 1049-85, Philadelphia, USA. 1997. Available from internet: https://www.astm.org/Standards/E1049.htm.

27. Bishop, N.W.M.; Lack, L.W.; Li T.; Kerr S.C. 1995. Analytical Fatigue Life Assessment of Vibration Induced Fatigue Damage, MSC World Users Conferance. Universal City, CA.

28. SolidWorks 2011. http://www.solidworks.com/sw/education/edulaunchmore.htm.
29. ANSYS 2012. http://www.ansys.com/products/academic/ansys-student.

30. Bishop N.W.; Sherratt F. 2000. Finite element based fatigue calculations. NAFEMS. Available from internet:https://www.nafems.org/publications/browse_buy/browse_by_topic/education/ht17/

31. MSC Software GmBH Online Help Documentation. 1999.

32. The Ncode Book of Fatigue Theory 2000, Ncode Technical Reference Book V4.3. Document rel 1.0, MSC. Corporation Available from internet: http://goo.gl/8wp4yI.

33. Bogdanoff J.L. 1978. A new cumulative damage model: Part I, Journal of Applied Mechanics, 45(2): 246250. Available in internet: http://appliedmechanics.asmedigitalcollection.asme.org/article.aspx?articleid $=1403814$.

\section{A.S. Sener}

\section{FATIGUE LIFE RESOLUTION OF THE STEERING WHEEL TIE ROD OF A LCV WITH FEA}

S u m m a r y

In this study, an accelerated test track construction necessary during research and development phase of Light Commercial vehicles (LCV) is described. By the questionnaire method, the Turkish customer automotive usages are defined. This paper focuses on defining load spectrum affected by steering wheel tie rod axial force derived during maneuvers. Finite Element Analyses (FEA) is used for fatigue analysis and it is verified by the Palmgren-Miner rule. As a result, lifetime of the part is calculated. An accelerated test tracks is designed for reliability and fatigue tests of the related company and linear FEA of the steering wheel tie rod represents a convenient procedure.

Keywords: Automobile usage, steering wheel tie rod, FEA, fatigue analysis, Palmgren-Miner rule.

Received August 18, 2016

Accepted October 13, 2017 